\title{
Upliftment of OTC Medicines Towards Innovative Marketing Strategies
}

\author{
G. Abarna, R. Shanthi
}

\begin{abstract}
Now a day, self- medication is becoming most easiest way for consumer. In spite of visiting doctors by spending their time and money for their minor illness many consumer has chosen to consume over-the-counter medicines (OTC). In order to capture these consumers the pharmaceutical company is using various marketing strategies to promote their company OTC medicines. The marketing strategy is an essential tool to promote their OTC medicine in an effective way. The purpose of this paper stands to explain the different types of marketing tactic used by the pharmaceutical company to detain in the market. This article also elaborates about OTC medicines, marketing strategies, advertising, promotion and its impact.
\end{abstract}

Keywords : OTC medicines, Marketing strategies, Advertising, Promotion, merits, demerits and its impact.

\section{INTRODUCTION}

$\mathrm{O}$ ver-the-counter (OTC) medicines are drugs, which is distribute to the patients directly without any prescription from a Registered Medical Practitioner(Doctors). In India, there is no legal recognition for the OTC medicines. The import, manufacture, distribution and sale of drugs and cosmetics acts regulated by the Drugs and Cosmetics Act (DCA) and its subordinate legislation, the Drugs and Cosmetics Rules $(\mathrm{DCR})^{1}$. It was said that not all the drugs that is include in the slope of 'prescription drugs' are deliberated as non-prescription drugs that is OTC medicines. Prescription Drugs falls under two schedules of the Drug and Cosmetics Rules, 1945.they are Schedule H and Schedule X. and some Drugs falls under Schedule G, these drugs require compulsory text on the label: "Caution: It is dangerous to take this preparation except under medical supervision" and the prescribed medicines are not advertise to the public by the industry $^{2}$.

\section{REVIEW OF LITERATURE}

Dzeparoski, M., \&Trajkovic-Jolevska, S. (2016) explains about the corresponding product category regulations is correlate with marketing strategy. $\mathrm{He}$ explained that emerging marketing approaches in the broader intellect aimed at, small to medium size concerns in each nations of interest with similar regulations and helps the companies to understand how to place and promote their products and company.
Amit Dwivedi and Gaurav Lodha (2015) explains that the Marketing strategies in Indian pharmaceutical industry have changed significantly for last decade, changes in marketing strategies will come up with new trials in the business environment. Therefore, the companies enormously promoting their companies' products to promote into the market.

Abhishek Dadhich and Kavaldeep Dixit(2015) describe that there are numerous healing segments are promoted by Pharma companies that facing lot of challenges through marketing strategies, enormously advertising and promoting their OTC product into the market helps the pharmaceutical companies to promote their product among consumer. The study highlight on various marketing strategies use to promote OTC brand in orderto satisfying need and wants of customer by pharmaceutical companies.

Valentina B. Petkova et al (2014) explained that the selling supervision includes investigation of market ventures, choice of target markets, scheduling, emerging and applying of marketing strategies, observing and control the result. Manufacturers marked complex corporative strategy for stimulating the sales

AjithPaninchukunnath (2007) describe that without full knowledge purchasing and practice of OTC drugs is not good for consumer's health. Generating consciousness of lucid medication use is likely by public education continuously through marketing strategy through a visualization of decent well-being and safety of the public.

Jaeun Shin and Sangho Moon (2005) he explained elevation of OTC medicines is a bag of assorted it educate consumers for their assistance and suitable usage of treatments.

\section{OBJECTIVES}

To know the innovative marketing strategy of over the counter (OTC) medicines

To know the impact of over the counter (OTC) medicines

To provide conceptual framework based on the reviews.

\section{RESEARCH METHODOLOGY}

The data for present study is collect from secondary sources such as online references, book references, magazines, journals and newspapers. 


\section{Upliftment of OTC Medicines Towards Innovative Marketing Strategies}

\section{MARKETING STRATEGIES OF OTC MEDICINES}

Planning a business action through strategy is an effective way to move the company toward its achievements of short term and long-term goals. Marketing strategies is the comprehensive plan that is an association of all marketing goals to deliver the organization value to its customer. These strategies helps in the growth and market expansion of OTC medicines in consumer health care sectors. Increasing personal spending, economic growth and access to Medicare are acting as a fuel in expanding Over the Counter market. In this case medical representative are also acting as a backbone for promoting their company products to physicians and others. Operating in niche category, fixing low price, selling of your own assets like divest strategy, presenting innovative and better-quality flavor, wrapping and distribution system container leads to extra and practical customer welfares in the pharma business. Pharmaceutical company can innovate their business in initiation fresh methods and quantities or demonstrate the product efficacy of new indication. Some of the innovative marketing strategy are:

\section{A. Emotional Influences}

Most of the people buy medicine not just for their favorite celebrity is promoting or celebrity treasures the beauty of the tablet attractive. According to their oldness, discomfort strength, the value of money, time consumption and many other factors, which influence the buying decision. The rational decision-making process is practice for purchasing health care product than other products. OTC products do not solve everyday problems. The OTC products are the currently present disaster, which solves disasters either minor major. By way of the disasters are relate to healthiness of our body, it organizes making intellect to effort to induce the sloppiness starved of existence besides overdramatic. Common goal for many OTC medications are pain treatment, and the entire impression of promoting announcement will show about the lack of the problematic. Touching the emotional chords of the people by confident explanation with singular pain relief is the most important tactic. The subsequent are communiqué efforts for meticulous entity.

\section{B. Purchaser Research}

Before buying a product for self-medication, consumer use to research about particular type of medicines with the help of social media and internet. Now a day's smart phone is very much helpful for doing this research at the place where they are, people always need the opinion of online expertise from authorized sources before doing self- medication to make them sure about causes and remedies of ailment. Therefore, it is important for the marketer to have a complete knowledge about the dominating keywords for search, frequently asked questions,common concerns etc. this enable the marketer to ensure that their product information available on the social media and internet is correct or not. If the information and communication is available in correct way to reach consumer, the better understanding and knowledge create benefit of buying that particular product is high. Clarity in beliefs among product is one of the most prominent force behind their buying decision.

\section{Staying on Consumers' Minds}

Customer comes to the pharmacy store, look what is available for minor ailment like Fever, cold and flu, headache etc., for consumption for their health. It is one of the advantage if the company if the company have "triumphs sales", of their medicines. However, it is also drawback to other companies. Since similar flora of OTC products cannot be sell by other industry, it becomes difficult for other products to frequently, remain in buyers' attentions. Therefore, the marketers can armed with social media, emails, and mobiles; through this, the marketer can have the capacity to make money available of alone who assumes of personalization.

\section{Evaluations and Analyses}

The essential part of any sales and creation part evaluation and analyses are constantly significant. The product will becomes a societal resistant effectively like a faith representation. If the patrons understand that the product is receiving extra admiration than a disapproval from a varied choice of people, it inevitably, the medicines of OTC has no modification from branded. Some medicines will work in good way for some people and for some people it will not in such a way positive appraisals more than negative people appraisals is adequate to deny the undesirable thoughts from the person who reads attention. By hearing the positive appraisals, the reader starts to feel positively about the product and that is what marketing is all about.

\section{E. Customer Loyalty}

Some of the OTC medications are consumption on need basis, some medicines as vitamins and supplements are generally consume daily basis. OTC medicines that was frequently use would make the OTC industry perfect for buyer faithfulness plans, which rise the buying frequency replication, even the customer have confidence in that loyalty programs are association with a business portion, and establish in what way trustworthy a firm is to them. Making or breaking a business is also depends on good loyalty program. Loyalty programs are also a treasure for the business in order to make smart invention endorsements to customer's base on their purchase contextual and more.

\section{F. Promotion of OTC medicines}

OTC drugs are promote directly to physicians and other healthcare professionals. The successful placing of OTC product can be done when Pharma company follow both directing and ethical promotional strategies.

\section{G. Advertisement}

No advertising is permit by the Drug \& Magic Remedies (Objectionable Advertisement) Act \&Rules, which is, references a slope of illnesses.

\section{Published By:}


There is no law which specific to prohibit the publicity of recommended drugs it is a manufacturing repetition is not to publicize physician recommended only drugs. The is certain standards have to maintain for advertising OTC drug they are advertising must be honest and non-deceptive; not likely to mislead consumers acting rationally under the circumstances, advertisers must have indication to back up their rights and advertisements must not be biased. The sales potency should have worthy data of creation and moral understanding with doctors as well as with retailers.

\section{H. Push and pull strategies}

Push and pull strategies are follow in OTC drug elevation. The push strategy ensures product availability by convincing retailers, chemist and doctors with full product knowledge and offers. This strategy promotes from the manufacturer to wholesalers, the wholesalers elevate it to retailers, and, at long last, retailers elevate the medication to patients. Organizations additionally elevate their items to pre-wholesalers, retailers or drug stores together or center around one of them.

A Pull methodology is about the maker advancing their item among the objective market to make request. So as to stock it buyers pull the item through the appropriation channel convincing the distributer and retailer.

\section{Sales promotion}

In order to increase short-term sales this strategy is used. Special offers and money off coupons are distributed. OTC Marketing corporations are perceived progressively associated with deal advancement in the new arrangements of present day exchange.

\section{J. Personal selling}

By using "sales force" selling the product after meeting face-to-face or directly to their customer, physician or pharmacist is called personal selling. Direct selling idea in OTC advertising can be do in an indistinguishable viable manner as saw in FMCG items.

\section{K. Direct mail}

An organization uses their resource effectively for publicity of substantial to the termed individual in the interior of their goal part through direct mail. By sending initialing advertisement the rate of response will increase it may leads to chances of improving sales

\section{MERITS}

Post office based mail enables an association to utilize their assets all the more successfully by enabling them to send exposure material to a named individual inside their objective portion. By customizing promoting, reaction rates increment along these lines expanding the opportunity of improving deals Direct mail enables an association to utilize their assets all the more viably by enabling them to send exposure material to a named individual inside their objective section. By customizing promoting, reaction rates increment in this way expanding the opportunity of improving deals Direct mail enables an association to utilize their assets all the more successfully by enabling them to send attention material to a named individual inside their objective portion. By customizing publicizing, reaction rates increment in this manner expanding the opportunity of improving deals. OTC medications are drugs that we get without specialist remedy and it help to avert and treat side effects of minor infirmities that do not require a specialist. OTC drugs lessen the weight on medicinal administrations when the doctors are inadequate. It encourages the patients to control their own interminable conditions. It benefits quiet health and productivity, financial addition for managers, and cost investment funds and diminish time on spending doctor visits. These target shielding of taking self-cured medications.

\section{DEMERITS}

Self-medicine have turned into a customary practice now a days it consumed quickly in to the neighborhood custom all through the world, their worldwide conveyance, legitimate showcasing and poor control imply that they are utilized and abused for a wide scope of utilizations . Abuse is utilizing an OTC item for a fitting medicinal reason however in higher portions or for a more drawn out period than suggest taking an over measurements may cause liver disappointment, Constipation, Skin rash or dermatitis, Diarrhea, Giddiness, Lethargy, Dry mouth, Headache, Restlessness. Prior to ingesting OTC medications, the client should realize how to devour or utilize the medications. The impacts and conceivable reactions of the medications just as methods for observing these symptoms, potential associations with different medications, span of the course of the medications must know by the buyer. They need to peruse the guidance given in the OTC mark.

\section{DRUG-DRUG INTERACTIONS}

Processes of every medicine react differently in our body. Taking medicines together, may distress the body and can modify. It is known medication sedate communication. It happens when we are expending OTC medications without an appropriate guidance. It might build the opportunity that reason reactions from prescriptions you are taking. The fundamental communication types are:

Copying: while taking dual medications, which consume parallel dynamic fixings. It can bounce additional prescription than required. Taking a lot of medicine will cause issues in kidneys or liver.

Opposition: while taking two meds, with the dynamic fixings that have inverse impacts can interface each other. This may diminish the adequacy of one or the two drugs.

Alteration: while taking two meds, One medication may change the method for body retains, spreads, or techniques another drug. 


\section{Upliftment of OTC Medicines Towards Innovative Marketing Strategies}

\section{IMPACT OF OTC MEDICINES}

Compared to branded medicines (prescription medicine) the OTC medicines price are low. People are consuming OTC medicines because it works and safe. Due to the value of money and time, trusted name, ease to take, quick in action, confidence in the product, etc. most of the public are taking it for their minor illness as an initial step. When you follow the directions on the label or as direct by your health care professional they are safe and effective.OTC drugs bear the cost of simpler access to treatment choices for regular conditions; contribute comfort, yet additionally opportune treatment and alleviation for minor illnesses. OTC medications not just critical to guaranteeing that buyers can access care that can act naturally oversaw, yet they are likewise essential to satisfying shoppers developing want to treat their own ailments, these items have demonstrated financial advantages also. The utilization of OTC prescriptions yields critical reserve funds to the two shoppers and the human services framework by diminishing superfluous doctor visits for generally self-treatable conditions.

\section{CONCLUSION}

In the event that OTC medications isn't accessible, purchasers looking for solutions for self-treatable conditions will increment and it would cause a stream in doctor visits that would require progressively extra full-time restorative experts to suit. The utilization of OTC prescriptions is expanding step by step. The pharmaceutical companies can promote their company product in the market in an effective way when the product encounters safety, efficiency, and make brand in the mind of consumers. For this purpose, the pharma company have to adopt effective promotional and marketing strategies to promote their products between the competitors in the market, they have to form strong relationship with the chemist and doctors and create positive brand on customers mind for long time in order to sustain in market. The sustainability can be achieve through suitable promotional and marketing strategies. It is like heartbeat of every companies and it should not be stable always. It have to change according to the reaction to the explosion of information, technology development, and the aggressiveness of competition etc.

\section{REFERENCES}

1. http:/cdsco.nic.in/html/Drugs \& Cosmetic Act.pdf

2. http://www.indiaoppi.com/OPPI\%20Code $\% 20$ of $\% 20$ Marketing $\% 20200$ 7.pdf

3. Dwivedi A. (2015) - A study on various marketing strategies used for promotion of OTC Drugs. International Multidisciplinary Research Journal

4. https/familydoctororg/otc medicines know your risks and reduce them/

5. Petkova V, Valchanova V, Ibrahim, A., Nikolova, I, Benbasat, N, \&Dimitrov, M. (2014). Marketing approaches for OTC analgesics in Bulgaria. Biotechnology \& Biotechnological Equipment, 28(2), 360-365.

6. Mullner R, Shin, J, \& Moon, S (2005) Direct-to-consumer prescription drug advertising concerns and evidence on consumers' benefit. Journal of Consumer Marketing.

7. Paninchukunnath A (2007) OTC Drug Marketing-Global Trends and Indian Experiences
8. Dzeparoski M \&Trajkovic-Jolevska S (2016) Analysis of marketing strategy for food supplements and over-the-counter medicines. Open access Macedonian journal of medical sciences, 4(3), 499.

9. https:/www.emedicinehealth.com/what are the risks of otc drugs/article emhtm

10. Abhishek Dadhich andKavaldeep Dixit (2015)trends in OTC drug marketing strategies by Indian pharmaceutical companies. World journal of pharmaceutical research Vol 4, Issue 10, 2015.

11. http:/ mohfwnic in

12. http:/ cdsconic inindex.html

\section{AUTHORS PROFILE}

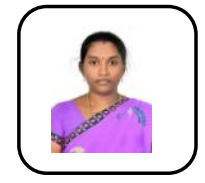

G. Abarna, pursuing doctoral research in the area of Marketing in the department of Commerce, University of Madras under the guidance of Dr. R Shanthi.An M.Phil and M.Com with First class. She has worked as an Assistant Professor during the year 2013 - 2016 in Vels University. She has participated and presented papers in National and International Conferences and also participated many Workshops. She has published paper in National and International Conferences referred journals. She has acted as an organizing member for National Seminar.

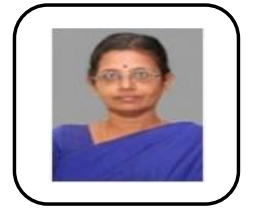

Dr. R. Shanthi is presently Associate Professor, Department of Commerce, University of Madras, Chennai. She has over 20 years of experience in the realm of marketing and banking. She has published paper in Peer reviewed journals, Newspaper and Edited Books. She has authored a book on Customer Relationship Management, Advanced Marketing, Data Analysis using SPSS and AMOS and organized three International conferences and four at national level. She has conducted training for corporate service on customer satisfaction and Brand equity. She has undertaken UGC - Major Research Projects. She is acting as Doctoral committee member for various University and colleges. She is in the examination board for affiliated college and University and a recipient Award for "Meritorious Services, Outstanding Performance and Remarkable Role" rendered in the Academic field. 